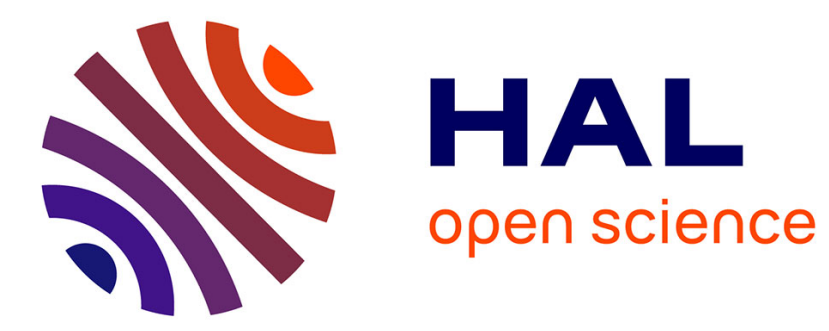

\title{
Determination of brazed joint constitutive law by inverse method
}

\author{
Georges Lovato, F. Moret, P. Le Gallo, Georges Cailletaud, Philippe Pilvin
}

\section{To cite this version:}

Georges Lovato, F. Moret, P. Le Gallo, Georges Cailletaud, Philippe Pilvin. Determination of brazed joint constitutive law by inverse method. Journal de Physique IV Proceedings, 1993, 03 (C7), pp.C71135-C7-1140. 10.1051/jp4:19937176 . jpa-00251807

\section{HAL Id: jpa-00251807 https://hal.science/jpa-00251807}

Submitted on 1 Jan 1993

HAL is a multi-disciplinary open access archive for the deposit and dissemination of scientific research documents, whether they are published or not. The documents may come from teaching and research institutions in France or abroad, or from public or private research centers.
L'archive ouverte pluridisciplinaire HAL, est destinée au dépôt et à la diffusion de documents scientifiques de niveau recherche, publiés ou non, émanant des établissements d'enseignement et de recherche français ou étrangers, des laboratoires publics ou privés. 


\title{
Determination of brazed joint constitutive law by inverse method
}

\author{
G. LOVATO, F. MORET, P. LE GALLO, G. CAILLETAUD* and P. PILVIN*
}

CEREM/Laboratoire de Génie des Matériaux, CENG, 85X, 38041 Grenoble cedex, France

${ }^{*}$ Centre des Matériaux de l'Ecole des Mines de Paris, UA 866 du CNRS, BP. 87, 91003 Evry cedex, France

\begin{abstract}
An important parameter often neglected for the calculation of residual stresses in brazed ceramic/metal assemblies is the joint constitutive law.

In situ camber measurements on a model system (axisymmetric TZM/InCuSil ABA/316L samples) performed using a special vertical dilatometer during the whole brazing thermal cycle are compared with results of FEM calculations based on published filler metal constitutive laws. A strong disagreement is observed.

Actual constitutive law of the joint is determined from these measurements using a numerical inverse method.

Calculated displacements are fully consistent with experimental ones. True solidification temperature of the joint is determined. The identified constitutive law of the joint exhibits a low flow stress from solidification temperature to $320^{\circ} \mathrm{C}$.
\end{abstract}

\section{INTRODUCTION}

Ceramic/metal joining is one of the key problem to enable a large industrial use of ceramic materials.

Due to CTE mismatch between ceramic and metallic materials, residual stresses are generated during cooling down of the assembly from joining temperature to room temperature [1-2-3]. Subsequent inservice thermal cycles can strongly modify these stresses. Prediction of these stress fields is necessary to avoid cracking and expand in service life of such bonded parts.

Today, no accurate validated method is available for the prediction of residual stresses in ceramic/metal assemblies due to several un-resolved problems, e.g. the singular point at the intersection of bonded plane and sample edge, knowledge of material constitutive laws from room to joining temperature especially for the joint e.g. interlayers and filler metal.

Brazing is an industrial technique to join ceramic and metals. Direct or active brazing is the simplest technology (no metallization treatment like Mo-Mn coating is necessary on the ceramic surface)[4-5]. The filler alloy contains an active element such as titanium. Brazing is then performed in inert atmosphere.

After cooling down, the brazed joint is the result of the complex physico-chemical reactions which occurred between the filler metal, the ceramic and the metallic substrate at liquid and solid state. Its thickness (10-100 $\mu \mathrm{m})$ does not enable any direct measurement of its mechanical properties except shearing experiments. The complexity (high temperature equipment, dimensional accuracy) and the lack of representativity of such experiments (large shear strains, long time exposure) explain that no accurate constitutive law is today available to describe the behaviour of the joints in finite element calculations.

Previous measurements of the evolution of the camber of plane ceramic-metal samples during the brazing cycle have shown a complex non linear behaviour due to the temperature dependence of the joint mechanical strength [6]. 
Firstly, in situ camber measurements on a model system (axisymmetric TZM/lnCuSil ABA/316L samples) performed using a special vertical dilatometer during the whole brazing thermal cycle are compared with results of FEM calculations based on published filler metal constitutive laws.

Then, true constitutive law of the joint is determined from these measurements using a numerical identification technique.

Calculated displacements are compared with experimental ones. The shape of the identified constitutive law of the joint is discussed.

\section{EXPERIMENTAL}

\subsection{Principle}

We have developed a specific testing method and apparatus for the determination of filler alloys constitutive laws. A vertical dilatometer "SETARAM DHT 2050" is used for in-situ measurement of the camber of flat bi-materials specimens during the whole brazing thermal cycle by measuring the probe displacements versus temperature. This computer controlled differential dilatometer with a graphite resistor furnace has been modified to work on large specimens under vacuum $\left(10^{-6}\right.$ mbar). Numerical records of time, temperature and displacement are obtained.

It is necessary to apply a $100 \mathrm{~g}$ load to perform the brazing. The dilatometer is calibrated with a reference material ("Pyros 56") : the accuracy on displacement amplitude is better than $2 \mu \mathrm{m}$.

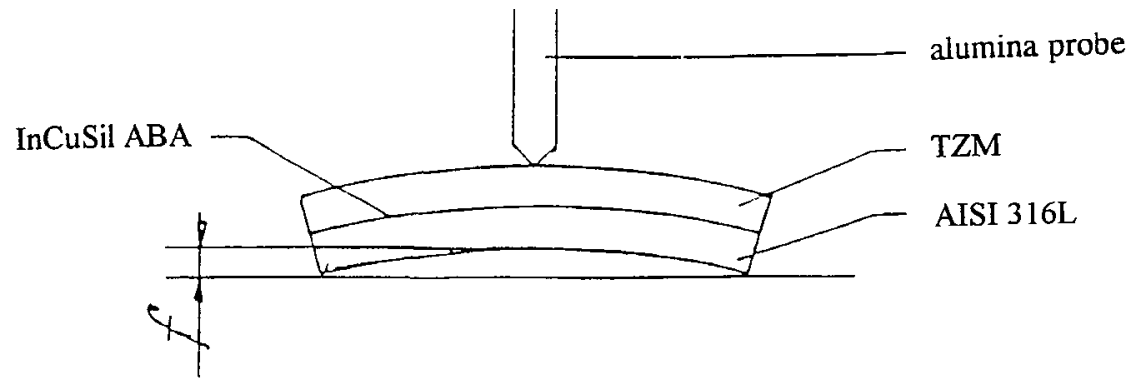

Figure 1 : Principle of in-situ measurement of the camber of bi-materials specimen in the dilatometer.

\subsection{Specimen preparation}

Molybdenum alioy and stainless steel specimens (Table 1) have been chosen as model systems for the following reasons:

.CTE mismatch comparable to a ceramic/metal assembly,

no cracking of the refractory material which can modify its mechanical properties,

.elastic behaviour of the refractory material due to its high yield strength up to brazing temperature, .well known constitutive laws of bulk materials.

The filler metal was InCuSil ABA, a Wesgo product often used for ceramic to metal brazing.

\begin{tabular}{|c|c|c|c|}
\hline Materials & Composition $(w \mathrm{t} \%)$ & Thickness $(\mu \mathrm{m})$ & Diameter $(\mathrm{mm})$ \\
\hline TZM & Mo-0.5Ti-0.1Zr & 700 & 13 \\
\hline AlSI 316 L & Z6CND17.11 & 2000 & 13 \\
\hline InCuSil ABA & Ag-26.6Cu-12.2/n-1.4Ti & 50 & 13 \\
\hline
\end{tabular}

Table 1 : Components of the dilatometric specimen.

Suitable parameters (temperature, atmosphere, time, kinetic) for brazing with an active filler metal have been determined. Special care was taken to obtain a correctly joined specimen, e.g. dimensional accuracy, constant braze thickness, wettability, and fillet geometry along the brazed surface (Fig.2). 

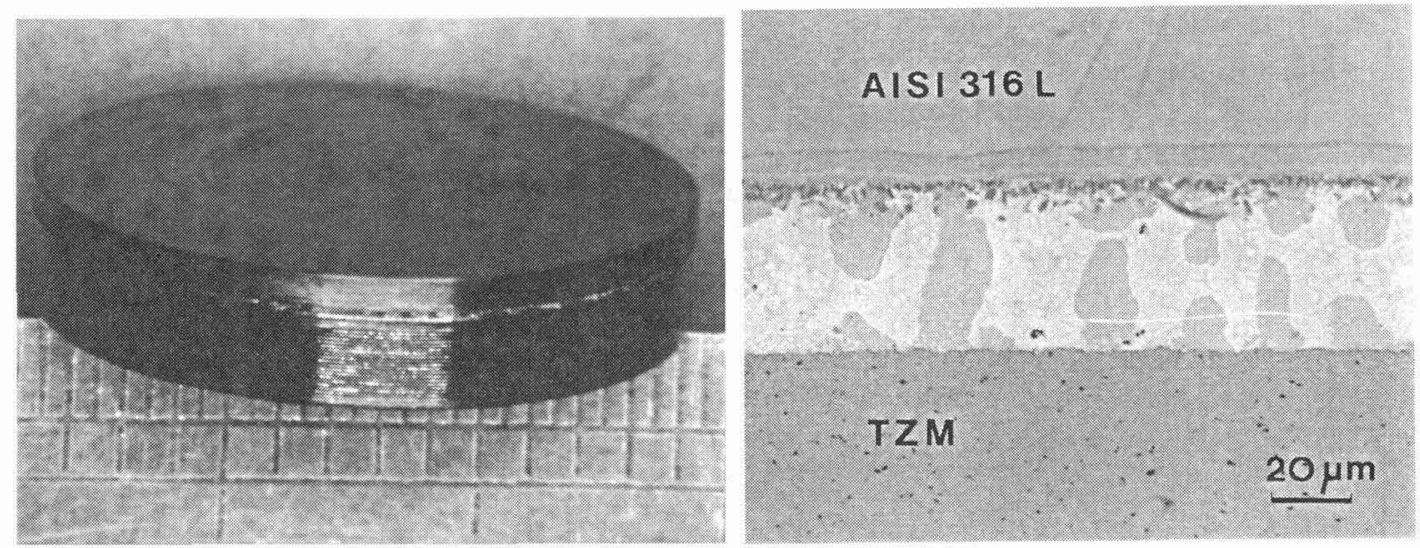

Figure 2 : a) TZM / InCuSil ABA / AISI 316L brazed specimen.

b) Metallography of the joint.

During heating until the melting of the braze, the dilatometric signal (Fig 3.a) corresponds to the thermal expansion of the materials and to the random flattening of the filler metal foil.

The melting of filler metal begins at $650^{\circ} \mathrm{C}$. This is $50^{\circ} \mathrm{C}$ higher than the solidus temperature quoted by Wesgo. Initially, the metal foil was $150 \mu \mathrm{m}$ thick; during melting the braze thickness decreases to $50 \mu \mathrm{m}$.

This thinning is enhanced by filler capillarity and fillet formation due to the reactivity of titanium. With InCuSil ABA filler metal, we observe a step by step melting, due to the dissolution of titanium. During the cooling down, two phenomenon exist :

- Camber formation due to the CTE mismatch,

- Inverse thermal expansion of the substrates.

A change in the slope of dilatometric record is observed at $360^{\circ} \mathrm{C}$.

Before $360^{\circ} \mathrm{C}$, camber formation is lower than inverse expansion, and below $360^{\circ} \mathrm{C}$ the magnitude of both effects are inverted. Moreover, the reversibility of this deformation has been observed: the cooling down and the following heating curve are similar.
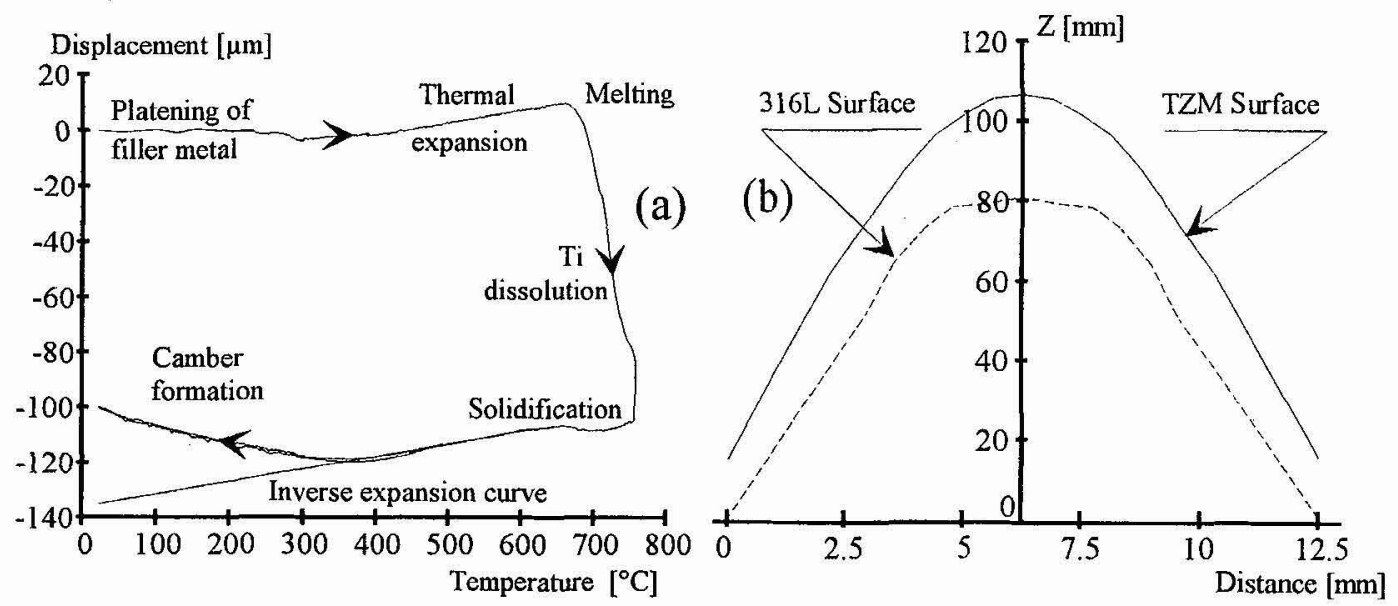

Figure 3 : a) Dilatometric record.

b) Measured profile of the dilatometric specimen.

A camber of the same value of the one deduced from dilatometric record is observed also on measured profiles of the specimen at room temperature in both directions (Fig. 3.b). 


\section{MODELLING RESIDUAL STRESSES BY FINITE-ELEMENT METHOD}

\subsection{Analysis method}

The FE mesh of the dilatometric specimen (Table 1) is shown in Fig.4.a. The stress and strain fields during cooling from a uniform temperature of $710^{\circ} \mathrm{C}$ lobserved solidification temperature, zero stress and strain state) to room temperature are calculated.

The FEM software, ZéBuLoN [6], is used with 2D thermo-elasto-visco-platic stress analysis and element type is the 8-nodal points axisymmetric element. The number of nodal points is 528 . Some of used thermo-elasto-plastic properties of TZM, AISI 316L and filler metal (InCuSil ABA and CB4 which have close properties) are given in Table 2. The material properties are temperature dependent. For AISI 316L, the elasto-visco-plastic model with non-linear kinematic and isotropic hardening of ref. [9] was used. For other materials, elastic-perfectly plastic models were used.

The deformed structure after cooling down from $710^{\circ} \mathrm{C}$ to RT is shown in Fig.4.a. Figure 4.b shows the axial stress $\sigma_{22}$ along the circumferencial free surface. The maximum of tensile stress is located on the TZM surface at approximately $5 \mu \mathrm{m}$ from the TZM/braze interface. This location was also observed with a ceramic or carbon fiber carbon material. This important tensile stress may induce Mode I crack initiation at this point.

\begin{tabular}{|l|lllll|}
\hline Material & $\mathrm{T}\left[{ }^{\circ} \mathrm{C}\right]$ & $\alpha\left[10^{-6} /{ }^{\circ} \mathrm{C}\right]$ & $\mathrm{E}[\mathrm{GPa}]$ & $v$ & $\sigma_{\mathrm{ys}}[\mathrm{MPa}]$ \\
\hline Filler metal & 20 & $18.95^{*} / 19.7^{* *}$ & $76^{*} / 79^{* *}$ & $0.3^{*} / 0.33^{* *}$ & $230^{*} / 235^{* *}$ \\
& 600 & $18.95^{*} / 19.7^{* *}$ & $76^{*} / 79^{* *}$ & $0.3^{*} / 0.33^{* *}$ & $25^{*} / 10^{* *}$ \\
$\mathrm{TZM} * * *$ & 20 & 5.3 & 300 & 0.32 & 600 \\
& 600 & 5.6 & 260 & 0.32 & 350 \\
AISI 316L**** & 20 & 15.7 & 196 & 0.29 & 250 \\
& 600 & 19.4 & 137 & 0.29 & 130 \\
\hline
\end{tabular}

* Data of CB4 from Kußmaul et al [5]

* In the case of the InCuSil ABA constitutive law given by Levy [4]

** Data from [10]

**** Calculated from the viscoplastic model used for AlS! 316L [9]

Table 2 : Some of the thermo-elasto-plastic properties of TZM, AISI 316L and InCuSil ABA used for calculations.
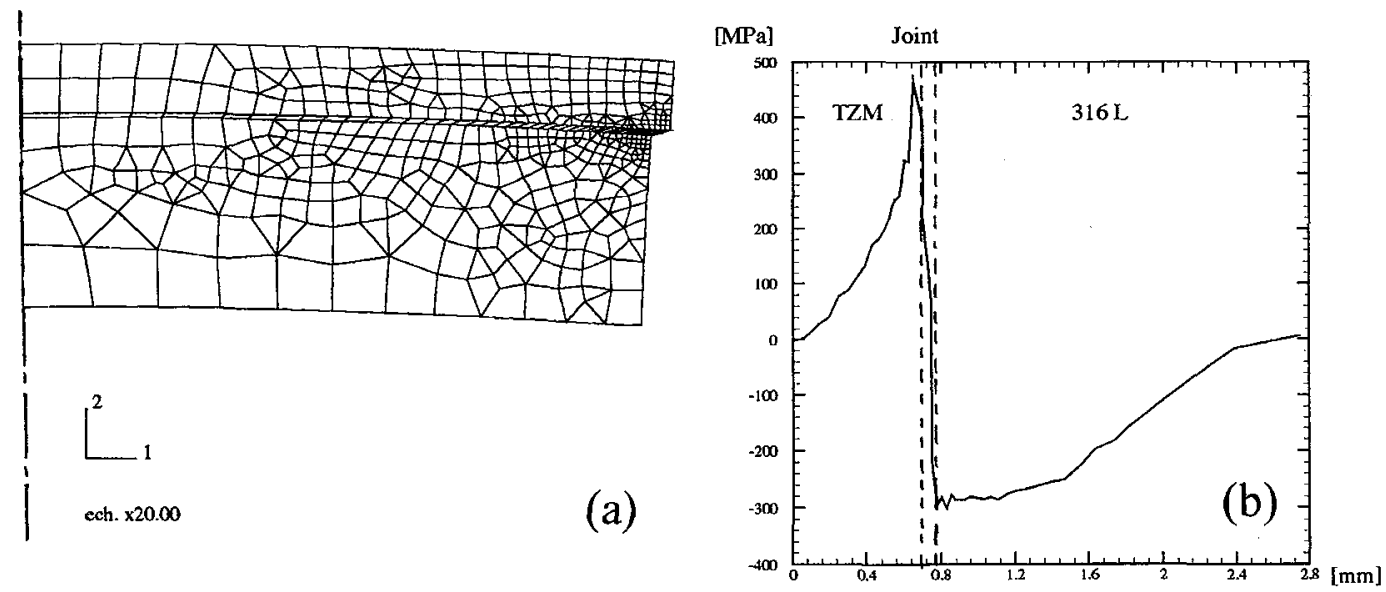

Figure 4 : a) Deformed mesh at RT after cooling down from $710^{\circ} \mathrm{C}$

(displacement magnification $\times 20$ ).

b) Residual axial stress along the circumferencial free surface. 


\subsection{Calculation results using filler metal constitutive laws}

Kußmaul et al.[5] and Levy[4] recently proposed constitutive laws for InCuSil filler metal and used them for FEM calculations of stresses in ceramic to metal assemblies. These two authors have assumed an elastic perfectly plastic behaviour. Elastic properties are not temperature dependent, and the yield stress is linear from $600^{\circ} \mathrm{C}$ to room temperature for the first one. Whereas Levy proposes a more realistic law (Fig.5.a).

The comparison of calculated dilatometric curves based on Kusßmaul and Levy laws with our dilatometric experiment shows a strong disagrement (Fig. 5.b).
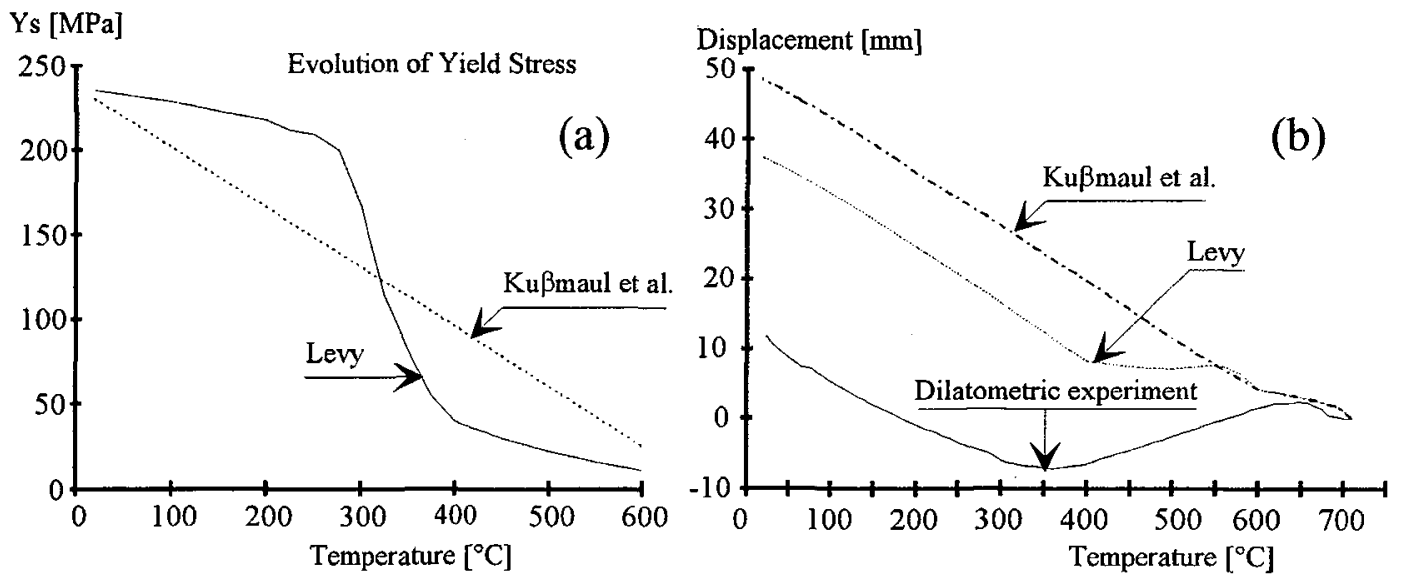

Figure 5 : a) Constitutive laws proposed by Levy[4] and Kubmaul et al.[5] for InCuSil and b) corresponding calculated dilatometric curves compared with experimental one.

\section{IDENTIFICATION OF JOINT CONSTITUTIVE LAW BY INVERSE METHOD}

\subsection{Principle}

The problem of the identification of constitutive laws is a classical engineering or research problem. After the building of a numerical model of the physical problem, as was described in 3.1 , the identification of the coefficients is made by solving an "inverse problem", which consists in founding the parameter set realising the best fit between experimental data and the model response [8].

Our method of validation is performed with a code acting together with ZéBuLoN. This code, called SiDoLo, is both a simulation tool for any kind of explicit or differential problems, including the solution of partial derivative systems in time and space, and a parameter optimisation tool.

SiDolo and ZéBuLoN are linked by means of an interface, which has three tasks :

- read the new coefficients proposed by the optimisation code,

- update the data file for the external code and make the run,

- read the results of the simulation code, compute the new values of the "observable" variables used by the following of the optimisation procedure.

\subsection{Identified joint constitutive law}

Adjusting the flow stress of the joint, identification using SiDoLo gives a very good fit with experimental result (Fig.6.a) and a physically acceptable constitutive law (Fig.6.b). The identified constitutive law is close to the one proposed by Levy but significantly lower below $500^{\circ} \mathrm{C}$. Such relatively small behaviour difference induces an excess of about $50 \%$ on the calculated stresses from Levy law. This first result indicates that the joint material is softer than the initial filler metal. This effect can be due to the coarse solidification microstructure of the joint and the reaction of the components (especially titanium) with the bulk materials. 

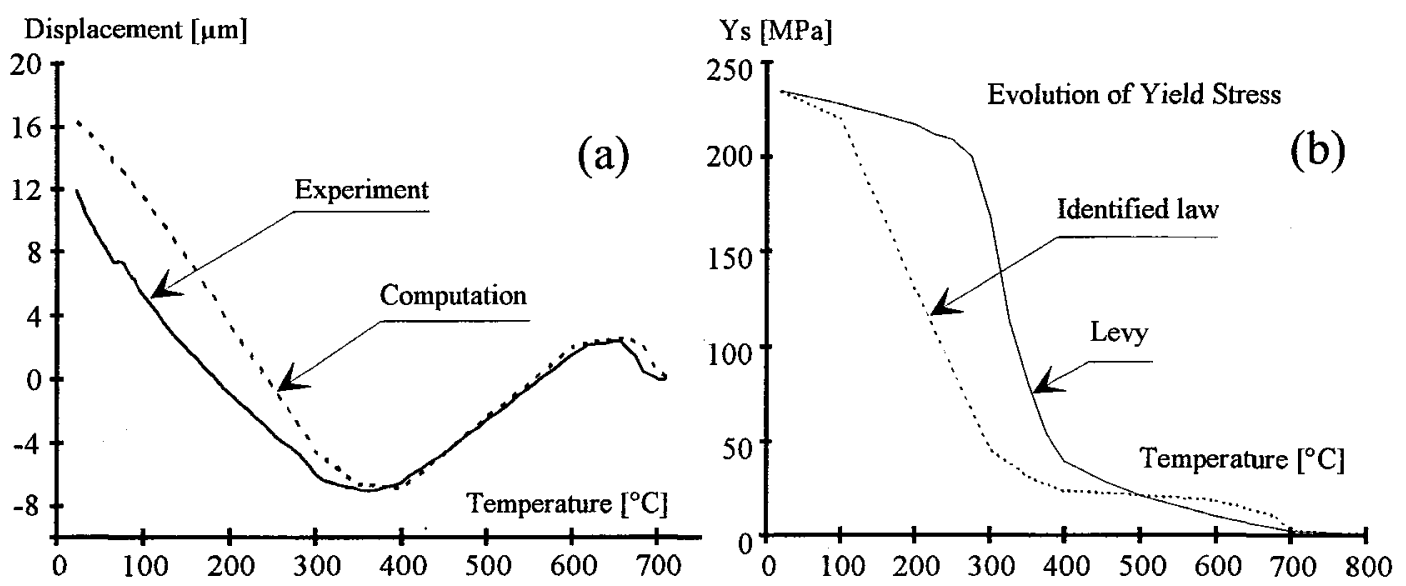

Figure 6 : a) Comparison between experimental and calculated results after the use of inverse method. b) Identified joint constitutive law compared with Levy data [4].

\section{CONCLUSIONS}

- The evolution of camber of bi-material specimens versus temperature from brazing temperature to RT can be accuratly measured using a special vertical dilatometer.

- A strongly non-linear behaviour is observed.

- Even for a simple axisymmetric specimen using well-known model materials (TZM and AISI 316L) and filler metal constitutive law measured on the foils (tensile test), we note a large discrepancy between FEM calculated camber evolution and experimental one $(50 \%$ in excess). Proportionnal errors are induced on estimated stresses.

- This disagreement is due to the microstructural and chemical differences between the filler metal foil and the joint.

- Inverse numerical methods allow the determination of thermo dependent joint constitutive law from dilatometric records.

- The elastic-perfectly plastic identified law for the InCuSil ABA braze joint between TZM and AISI $316 \mathrm{~L}$ exhibits a plateau at a low stress value down to $400^{\circ} \mathrm{C}$. Large shear strain concentration is observed in the joint.

\section{REFERENCES}

[1] P.O. Charreyron, D.O. Patten, and B.J. Miller, Ceram. Eng. Sci. Proc., 10 [11-12] 1801-24 (1989).

[2] A. Levy, J. Am. Ceram. Soc., 74 [9] 2141-47 (1991).

[3] R. Kußmaul, D. Munz, Proc. 4th International Conference, Joining ceramics, Glass and Metal, pp.152-159 ,May 17-19, 1993, Konigswinter (Germany).

[4] K. Suganuma, Y. Miyamoto, M. Koizumi, Ann. Rev. Mater. Sci., $18: 47-73$.

[5] H. Mizuhara, Huebel E.,Oyama T., Ceramic Bulletin, 68 No9 (1989) 1591-1599.

[6] G. Chaumat, G. Lovato, P. Lemoine, Proc. of the 17th Symposium on Fusion Technology, Rome, (Italy), 14-18 sept.1992, Vol.1, pp.218-222, Elsevier Science Publishers 1993.

[7] H. Burlet, G. Cailletaud, Proc. Coll. Greco-CNRS "New Advances in Structural Calculations"; Giens (France), 15-18 mai 1991.

[8] G. Cailletaud, P. Pilvin, Proc. Coll. national en calcul de structures, Giens (France), 11-14 mai 1993, pp.770-787, Vol.2, Hermes, Paris.

[9] J. Lemaitre, A. Benallal, A. Ben Cheikh, R. Billardon, J. Duffailly, L .Feng, J. FLorez, M.T. Gautherin, G. Geymonat, C. Lienard, D. Marquis, D. Mertz, L. Moret-Bailly, Formulaire de Caracteristiques Mécaniques de Matériaux, Rap. Int. n 72, Juin 1987, L.M.T. E.N.S. de Cachan, Univ. Paris 6.

[10] NET Team E.Z., "Green Book", Material Data, 2nd Edition, Garching, Germany (1991) 